\title{
"Não mais yanaconas modernos": tempo e legitimação histórica em um experimento historiográfico Misak (Cauca - Colômbia)
}

\section{"No more modern Yanaconas": time and historical legitimation in a Misak historiographical experiment (Cauca-Colombia)}

Guilherme Bianchi*

*Universidade Federal de Ouro Preto - Ouro Preto, MG, Brasil

Doutorando em História

guilhermebianchix@gmail.com

https://orcid.org/0000-0002-8907-9426 


\title{
Resumo
}

Tendo como foco a produção intelectual desenvolvida recentemente pelos Misak que habitam o território de Guambía, na Colômbia andina, quero demonstrar de que forma a reapropriação criativa do discurso histórico nacional funciona, nesse contexto, como um dispositivo político de legitimidade interna e externa. A partir da análise de um experimento historiográfico posto em jogo pelo Comité de Historia del Cabildo Guambiano a partir do final da década de 1980, argumento que as concepções sociais de tempo e a ressignificação indígena dos vestígios históricos escritos podem ser lidas como partes complementares de um mesmo movimento, a saber, de uma luta política por legitimação histórica que se dá no interior de um litígio cosmológico.

Palavras-chave: historiografia; tempo; Misak; Colômbia.

\begin{abstract}
Focusing on the intellectual production developed recently by the Misak who inhabit the territory of Guambía, in Andean Colombia, we will try to demonstrate how the creative reappropriation of the national historical discourse functions, in this context, as a political device of internal and external legitimacy. Through the analysis of an historiographical experiment created by the Comité de Historia del Cabildo Guambiano on the late 1980's and the 1990's, we argue that the social conceptions of time and the indigenous resignification of written historical records can be read as complementary parts of the same movement, namely, a political struggle for historical legitimation that takes place within a cosmological dispute.
\end{abstract}

Keywords: historiography; time; Misak; Colombia. 
Consideramos que la memoria oral, las toponimias, los lenguajes del territorio deben ser categorizados como elementos fundamentales para la reconstrucción de la memoria y no la historia escrita por el victimario. Estamos escribiendo nuestra historia pero en nuestro propio lenguaje. Mama Liliana Pechené, governadora do cabildo Misak

\section{Introdução}

Os Misak habitam um território no sudoeste da Colômbia e somam hoje cerca de 26 mil indígenas, presentes em seis departamentos do país. A maior parte dos Misak (cerca de 15 mil) reside hoje no resguardo indígena ${ }^{1}$ de Guambía, no município de Silvia, uma pequena cidade majoritariamente rural, localizada a duas horas de carro da capital do departamento, Popayán. Silvia se localiza no departamento colombiano do Cauca, na parte ocidental da cordilheira central, um dos três principais ramos nos quais a cordilheira dos Andes está dividida no país. Do total de 32 mil habitantes da cidade, quase $80 \%$ são compostos por indígenas, em sua maior parte indivíduos da etnia Misak, mas também Nasa (Páez) e Ambalueños. Ao redor da cidade, além de Guambía, uma série de comunidades indígenas ocupam o território de outros resguardos (Chilito, 2018).

Após o processo de independência da Colômbia, no começo do século XIX, muitos dos territórios que haviam sido designados como resguardos indígenas desde as primeiras décadas da colonização foram declarados vazios. Os legisladores consideravam que as comunidades que seus habitantes um dia haviam formado teriam deixado de existir em algum momento entre o passado colonial e o presente republicano. A figura jurídica colonial do resguardo justificava-se, naquele tempo, pela necessidade da coroa espanhola de garantir mão de obra e provisão de alimentos, como forma de limitar a exploração dos indígenas e a entrega de terras aos conquistadores, ao mesmo tempo mantendo os nativos nos trabalhos de cultivo. Conquistada a independência, e em boa parte dos séculos XIX e XX, uma série de decretos e leis efetivaram a dissolução,

1 No Cauca, os Misak se concentram, de maneira preponderante, nas seguintes cidades e respectivos resguardos: Silvia (Guambía), Piendamó (La María e Pisicitau), Morales (San Antonio e Bonanza), Cajibío (Kurakchak), Tambo (Guambía) e Caldono (Liberia). 
a divisão e a repartição das terras de resguardos declaradas vazias (González, 1979; Herrera Ángel, 1998).

Seria só a partir de 1990 que o governo colombiano passaria a reconhecer uma série de direitos indígenas relacionados à autonomia política e administrativa, ao território e à educação intercultural dos grupos tradicionais - reconhecimento que, vale assinalar, resultou, ao menos em parte, de uma pressão nacional dos movimentos indígenas colombianos, mais intensa a partir da década de 1960 (Sánchez Gutiérrez; Molina Echeverri, 2010). Uma direção fundamental desse contexto político foi o reestabelecimento dos territórios tradicionais para comunidades indígenas que haviam historicamente perdido o direito de habitar seus territórios ancestrais, novamente sob a figura jurídica do resguardo, agora como um título de propriedade coletivo e inalienável, com o objetivo de proteger institucionalmente tanto o território quanto a autonomia cultural e a política indígena sobre a gestão territorial (a possibilidade, por exemplo, de esse território ser regido por uma jurisdição própria às comunidades indígenas, a jurisdicción especial indígena²). O efetivo sucesso das lutas por recuperação territorial e refundação de inúmeros resguardos é evidenciado por sua intensa presença, nos dias de hoje, em regiões que concentram grandes cifras de população indígena, como é o caso do Cauca.

Essas aberturas políticas constitucionais foram acompanhadas por uma rica paisagem histórica na qual o protagonismo dos povos indígenas colombianos, mediada por experimentações políticas, criações de conceitos, elaborações criativas de formas de organização, etc., foi determinante para o realinhamento recente da participação indígena no espaço público nacional. Na medida em que procuravam se adaptar às novas circunstâncias políticas do país (a criação de espaços institucionais que buscavam possibilitar uma representação efetiva das comunidades indígenas na sociedade civil colombiana) novos discursos e estratégias foram criadas pelos movimentos indígenas, visando a possibilidade de agir dentro de campos específicos do Estado colombiano: a jurisprudência, o desenvolvimento, a educação, a saúde, etc. De acordo com Rappaport e Gow (2003, p. 47), nesse processo de amplitude nacional, uma multiplicidade de novos atores indígenas acabou por emergir. Jovens homens e mulheres, em sua

2 Sobre a história e o funcionamento da jurisdição especial indígena na Colômbia, cf. Sánchez Botero (2005) e Yrigoyen Fajardo (2008). 
maioria, com algum grau de instrução formal, e inclinados a ocupar os espaços (discursivos e políticos) entre suas comunidades e a sociedade nacional. São esses "gestos" - gestos que reafirmam a política como uma experiência da diferença, representada aqui pelo impulso de criação de novas conexões sensíveis entre os Misak de Guambía e a sociedade nacional colombiana - que enfatizarei a seguir.

A presença política da jovem líder do cabildo Misak (como é chamado seu órgão político-administrativo central), Liliana Pechené, produz um contraste radical com o tipo de organização histórica dos Misak, onde homens mais velhos (mayores) tradicionalmente ocuparam os cargos de liderança política. A posição que mama Liliana ${ }^{3}$ passou a exercer nos últimos anos - e que, de certa maneira, resultou no protagonismo político dos Misak em meio ao processo do acordo de paz entre o governo colombiano e as Fuerzas Armadas Revolucionarias de Colombia (Farc) ${ }^{4}$ - é fruto de um longo processo de reconhecimento, pelos mayores, da centralidade dos elementos endógenos da cultura indígena como ferramentas potencialmente disruptivas no interior de disputas políticas institucionais, como veremos ao longo do texto. Mas, apesar de seu protagonismo político em Guambía, foi só em janeiro de 2017 que Liliana assumiu a posição de governadora, o cargo máximo de liderança do cabildo.

Politicamente, vários grupos indígenas da Colômbia estão organizados sob a forma de cabildos indígenas. O cabildo é, desde a última década do século XIX, a forma organizativa pela qual os grupos indígenas foram representados nacionalmente em âmbitos institucionais. ${ }^{5}$ Não se foram menos de cem anos, entretanto, para que fossem finalmente reconhecidos como sujeitos coletivos

3 Mama e taita são, respectivamente, a forma feminina e masculina pela qual se denominam costumeiramente os Misak mais velhos (os mayores). A expressão, no entanto, também é usada para denominar aqueles que fazem parte do cabildo Misak ou ocupam cargos de liderança em sua estrutura administrativa, sendo mais velhos ou não.

4 Em 2016, Liliana fez parte da comitiva que acompanhou o então presidente do país, Juan Manuel Santos, na cerimônia de recebimento do Prêmio Nobel da Paz, entregue como reconhecimento dos esforços de seu governo na luta pelo fim da duradoura guerra civil vivida na Colômbia desde os anos 1950. Sete personalidades públicas o acompanharam, como representantes dos grupos vitimados durante o conflito, e Liliana foi a escolhida para representar as vítimas indígenas.

5 Ver o texto da lei 89 de 1890, "por la cual se determina la manera como deben ser gobernados los salvajes que se reduzcan a la vida civilizada" (Colombia, 1890). 
autônomos, e possibilitados assim de administrar a terra de seus resguardos com uma "administração de sistema própria aos povos indígenas". O cabildo é a forma da "autoridade tradicional" dos grupos indígenas em seus resguardos. A estrutura do cabildo Misak (até muito recentemente chamado de cabildo guambiano) é formada por um governador, um vice-governador, além de secretários locais, fiscais e tesoureiros. A mudança recente do etnômino "guambiano" para o nativo "Misak" (grafado mais antigamente como "Misag", e hoje em dia também como "Wampia" ou "Misak Misak") é parte desse movimento de reapropriação identitária local emergente nas últimas décadas, mas foi definitivamente instituído em um comunicado à sociedade nacional em 2005 onde reivindicavam a substituição formal do termo:

Como es conocido por todo el mundo, nosotros el pueblo Wampia o Misak, a quienes nos han llamado guambianos, hacemos parte de los primeros pobladores de estas tierras: Abyayala, Unayala o Nupiraw antes de que las llamaran América, del Kauka, que en nuestra lengua significa madre de los bosques y a la que la Unesco ha declarado reserva estratégica de la biosfera, de Wampia, que significa "hijos de la palabra, los sueños y el agua", así como de lo que la historia falseada que educa y reconoció en Colombia que el Gran Kauka, que era desde el Chocó hasta Quito Ecuador. (cf. Parrado-Morales; Isidro, 2014, p. 137, grifo dos autores).

Antes de ocupar o cargo de governadora, Liliana esteve diretamente envolvida em um projeto de reconstrução da memória histórica indígena, junto com outros jovens de Guambía. Esse projeto, que consistiu na visita a arquivos históricos de Popayán, Bogotá, Lima e Sevilla, com o objetivo de recuperar o conhecimento produzido historicamente sobre os "guambianos" a partir da conquista espanhola, funcionou como reafirmação de uma percepção sobre as lacunas conceituais entre as formas Misak de conhecimento e aquelas produzidas por atores externos (Tunubalá; Pechené, 2010). Recentemente em um seminário em Bogotá, Liliana ressaltou a necessidade mesma de repensar o uso da palavra "arquivo" para se referir às produções internas em Guambía referentes ao passado: "Arquivo é guardar [...] talvez seja melhor falar em registros de memória, de pensamento. Porque estão mais arraigados e mais vivos. Um território não pode ser uma focalização. O que você precisa entender é que o território como meio de vida não pode ter uma conotação de arquivo" 
(tradução minha). ${ }^{6}$ Em outros momentos, como no trecho da epígrafe, Liliana enfatiza a necessidade de que as "linguagens do território" sejam categorizadas como elementos fundamentais para a reconstrução da memória, "e não a história escrita pelo perpetrador".

Mas essa tentativa de escrever a história Misak por um tipo de linguagem própria se efetivará pela primeira vez alguns anos antes, em um experimento específico nos anos 1980 e 1990. A posição atual de Liliana, e a forte politização do discurso Misak no presente, é, de certa maneira, efeito direto de um processo histórico mais geral de remissão da luta política indígena a categorias cosmológicas e de identidade cultural, e guarda origem nas transformações políticas da segunda metade do século XX na Colômbia. ${ }^{7}$ Da forma como tentarei argumentar, esse tipo de cruzamento entre a disputa política externa e a afirmação das especificidades interiores dos Misak aparece como uma constante em sua história recente, onde a ênfase na diferenciação cultural permite um espaço para o estabelecimento de um critério (político) para ação no presente. Nesse caso, as conexões parciais entre as dinâmicas endógenas da comunidade e as brechas institucionais (e constitucionais) do Estado colombiano efetivam uma reapropriação criativa do conhecimento histórico colonial em seus projetos políticos recentes que, por sua vez, são informados e postos em prática em torno da cosmologia local. ${ }^{8}$

De maneira complementar, a história recente da politização indígena no Cauca colombiano, representada aqui pela experiência do resguardo de Guambía - e entendendo por politização tanto a inserção ativa de seus indivíduos no campo político nacional como a mobilização política da cosmologia

6 Fala proferida no evento "Encuentro sobre archivos de DDHH, oralidad, territorio y comunidades indígenas" realizado em 16 de julho de 2014 no Centro Nacional de Memoria Histórica, Bogotá, Colômbia.

7 A história mais recente da atuação política de Liliana e a importância de sua experiência prática nos arquivos históricos são temas de uma pesquisa ainda em andamento.

8 Movimento semelhante ao indicado por Terence Turner no início dos anos 1990 para o caso das comunidades indígenas no Brasil: manutenção de ritos, mitos e de instituições sociais tradicionais como parte integral da luta indígena contra a perda de terras, recursos e condições de autodeterminação. A afirmação cultural, nesse sentido, como aquilo capaz de tornar visível a agência dos povos indígenas em relação à sociedade nacional. Pois, na medida em que passam a assumir uma nova importância política e teórica "como atores em seu próprio benefício, como pessoas e agentes, e não como vítimas", como escrevia Turner (1991, p. 69), mais importante se torna a tarefa de "compreender seus padrões ideológicos e suas formas de ação coletiva". 
Misak na vida prática - aparece como lugar privilegiado para uma averiguação das relações, interações e inevitáveis desencontros entre a luta política, as formas simbólicas e os modos de existir. O "presente histórico" dos Misak como lugar de irradiação de imagens de mundo "míticas", como cosmologia política, menos como "superestruturas" passivas de um interesse instrumental mais determinante, e mais como entidades fundamentalmente políticas no sentido de que são capazes de negociar sentidos sobre o cosmos: entidades produtoras de ação no mundo.

Ao longo do artigo, esses apontamentos serão direcionados em torno do estudo de um esforço pontual surgido em Guambía num projeto de autonomia histórica e historiográfica dos Misak. Nessa experiência, coexistirão um esforço intelectual de crítica das fontes históricas como modo de justificação temporal do direito indígena ao território (o "valor" dessa história sendo medido por sua capacidade de legitimar o pertencimento territorial) e a criação teórica de conceitos endógenos baseados na relação entre tempo e território. Dois momentos que ajudam a entender a dinâmica das práticas políticas indígenas em Guambía dos dias atuais e a relação entre legitimidade histórica e pertencimento territorial. A hipótese é a de que, mais do que uma reconstrução histórica do passado indígena baseada na confrontação entre fontes ocidentais e a memória oral, a orientação política da atividade histórica indígena aponta também para a justificação de uma particular experiência do tempo - exercício historiográfico que é, ao mesmo tempo, imagem de um modo de vida que é outro.

\section{Usos Misak do passado histórico}

Depois de um relativo sucesso dos processos de luta e reivindicação pública de antigos territórios sagrados nos anos 1960 e 1970, os Misak de Guambía, já organizados sob a forma de cabildo, passaram a indicar a necessidade de empreender uma luta para, como dizem desde então, "recuperar tudo". "Tudo", nesse sentido, significava aquilo que, para além do direito à ocupação territorial, os séculos de luta por sobrevivência existencial também acabaram por enfraquecer: os costumes locais, as leis tradicionais, a história (e a concepção de história), os usos da terra, a educação tradicional, os mitos, a concepção do território, os antigos modos de organização política, etc. Uma reunião em Guambía em 1980, 
conhecida hoje como Primera Assemblea, produziu um documento que, até os dias de hoje, possui grande valor histórico e político para o cabildo. O manifesto resultante dos trabalhos ali realizados - o "Manifesto Guambiano" de 1980 anunciava que o trabalho de recuperação da identidade não poderia ser levado a cabo sem o trabalho de recuperação de seus territórios ancestrais: "recuperar a terra para recuperar tudo". A luta territorial também dependia, no entanto, e de maneira complementar, de uma reorientação cultural a partir de conceitos endógenos - a cultura "própria", o direito "próprio", o saber ancestral, etc.

Recordando los derechos y las luchas de los mayores pensamos en nuestra propia cabeza y pudimos ver que los guambianos por encima de todo tenemos algo en común: el derecho a recuperar nuestra tierra, el derecho a fortalecer nuestro gobierno indígena, el derecho a desarrollar nuestras costumbres, el derecho a impulsar nuestra vida comunitaria, el derecho a dirigir nuestro propio destino. (Cabildo del Pueblo Guambiano, 1980).

Na senda aberta pela Primera Assemblea - e, portanto, pela necessidade de afirmação identitária como gesto inseparável da luta política pela recuperação dos territórios ancestrais - o cabildo decretou a criação de uma série de comitês de trabalho na comunidade. Entre comitês de saúde, educação, linguística, justiça, etc., um comitê dedicado à história, uma iniciativa que deveria se basear na colaboração entre pesquisadores indígenas e profissionais universitários (chamados de solidarios). ${ }^{9} \mathrm{O}$ objetivo principal do Comité de Historia del Cabildo Guambiano, como passou a ser chamado, era a recuperação dos saberes ancestrais e a reconstrução histórica do passado Misak. Essas eram informações que, ao final do século XX, dificilmente circulavam internamente no resguardo depois de um processo de esquecimento que dominou a região diante da mordaça imposta pela doutrinação e pela educação religiosa dos séculos XIX e XX.

Segundo o antropólogo colombiano Luis Guillermo Vasco Uribe (e um dos solidarios), os três primeiros anos de atividade (1982-1984) foram importantes para a realização de um trabalho de convencimento e encorajamento dos indígenas mais velhos, ainda muito reticentes em compartilhar histórias que,

9 Sobre o contexto de criação dos comitês, ver Cabildo del Pueblo Guambiano (1994) e também Acosta (2013). 
por tanto tempo, haviam permanecido ocultas, sob uma espécie de silêncio coletivo. Se o objetivo primordial e mais urgente era a recuperação de terras, o cabildo percebeu que, uma vez reconquistadas - e como pretendiam ocupá-las e administrá-las a partir de seus conhecimentos próprios de agricultura - tornava-se necessário recuperar, junto ao solo, os saberes sobre ele. A iniciativa do comitê se justificava, assim, primeiramente pela possibilidade de recuperar os conhecimentos transmitidos pela tradição oral dos mayores, buscando produzir respostas a um problema de natureza prática, surgido desse esquecimento coletivo. Como lembram alguns membros do comitê sobre a lacuna de elementos históricos para basear o trabalho de recuperação territorial:

Cuando las tierras de la Hacienda Las Mercedes, su primer objetivo, estuvieron de nuevo en sus manos [1980], se propusieron manejarlas a la manera propia y no a la de los blancos, basada en la propiedad individual de unos pocos para su enriquecimiento, sólo para descubrir que, después de cinco siglos de dominación y negación, habían olvidado el camino abierto por los anteriores y no tenían claro cuál era el modo propio guambiano de acceder a la tierra y trabajarla. (Dagua Hurtado; Aranda; Vasco Uribe, 2015, p. 11).

O valor dos aspectos do passado empregados nessa prática decorre, como podemos ver, de sua potencial "utilidade", para recuperar a sempre oportuna imagem nietzschiana de uma história "a serviço da vida". O comitê sendo concebido, assim, como um dispositivo para a reativação de certas práticas ancestrais: métodos agrícolas tradicionais, formas endógenas de conceber o território, modos de organizar o tempo e de se organizar politicamente no presente, etc.

Alguns resultados das primeiras atividades do comitê foram publicados em uma série de seis pequenos livros, entre 1988 e 1994, quase sempre identificados pela autoria do Comité de Historia del Cabildo Guambiano, dos taita Misak e membros do comitê Abelino Dagua Hurtado e Misael Aranda, além do antropólogo solidario Luis Guillermo Vasco Uribe, da Universidad Nacional de Colombia. Originalmente tratava-se de textos impressos em folhas mimeografadas, de circulação interna e, em alguns casos, de pequena circulação externa, frutos de numerosas entrevistas e conversas gravadas entre os membros do comitê e os mayores - Vasco Uribe lembra que "os guambianos foram o primeiro grupo indígena da Colômbia a se apropriar e usar em massas os gravadores. Em todos 
os lugares, durante a luta, eles andavam com um gravador, baterias e fitas cassetes" (Vasco Uribe, 2007, p. 28, tradução minha). O objetivo dos textos, como explicaram os autores, era o de criar ferramentas que pudessem contribuir para a reprodução comunitária, bem como para seu crescimento "sobre princípios arraigados em sua tradição e seu pensamento próprio, e tratar de deter o processo acelerado de deterioração do páramo e da perda da água" (Dagua Hurtado; Aranda; Vasco Uribe, 2015, p. 11, tradução minha). A partir do final dos anos 1990, alguns desses materiais começaram a ser republicados em livros e revistas colombianas de antropologia, que hoje podem ser encontrados com alguma facilidade..$^{10}$ Atualmente, parte do material continua sendo utilizado em cursos de profissionalização para professores indígenas no Cauca.

Há duas questões, presentes em alguns desses livros produzidos pelo comitê, que parecem de fundamental importância para pensarmos a relação entre a história escrita e as formas de subjetivação do tempo Misak. São elas a legitimidade do pertencimento territorial (sobre como legitimar historicamente a ocupação dos territórios ancestrais recuperados ou em recuperação) e o problema da concepção e da experiência temporal Misak (de que forma derivar a relação entre os sujeitos e o território a partir de um conceito próprio de temporalidade). Uma hipótese é que, se o exercício historiográfico indígena, nas atividades do comitê, funcionou ele mesmo como ferramenta de legitimação territorial - a disputa por uma historiografia "própria" como maneira de politizar suas próprias formas de temporalidade -, então o desenvolvimento de uma concepção de espiralada de tempo (o "tempo caracol", como veremos na seção seguinte) se conecta, de maneira semelhante, a um certo impulso de espacialização da experiência histórica dos Misak, já que essa experiência deriva-se de uma relação específica entre tempo e território, na qual a possibilidade de reconhecimento histórico está calcada não apenas na tradição oral dos mayores, mas também impressa e contida no nupirau, no território ancestral.

10 Os livros são: Korosraikwan issukun (1988); Somos raízy retoño (1989); Calendario guambiano y ciclo agrícola (1990); Sembrary vivir en nuestra tierra (1991); En el segundo día, la gente grande-Numisaksembró la autoridad y las plantas y, con su jugo, bebió el sentido (1993); Srekollimisak: historia del señor aguacero (1994). Em 1998 todos os livros foram republicados com textos adicionais no livro Guambianos: hijos del aroiris y del agua (Dagua Hurtado; Aranda; Vasco Uribe, 2015). A maioria dos textos pode ser encontrada no website pessoal do solidario Luis Guillermo Vasco Uribe, em http://www.luguiva.net/. Sobre sua participação em torno do comitê, ver Vasco Uribe (2007). 
Pois, como afirmam, "para ouvir o que esse [território] tem a dizer, é preciso caminhar por ele" (Dagua Hurtado; Aranda; Vasco Uribe, 2015, p. 13, tradução minha).
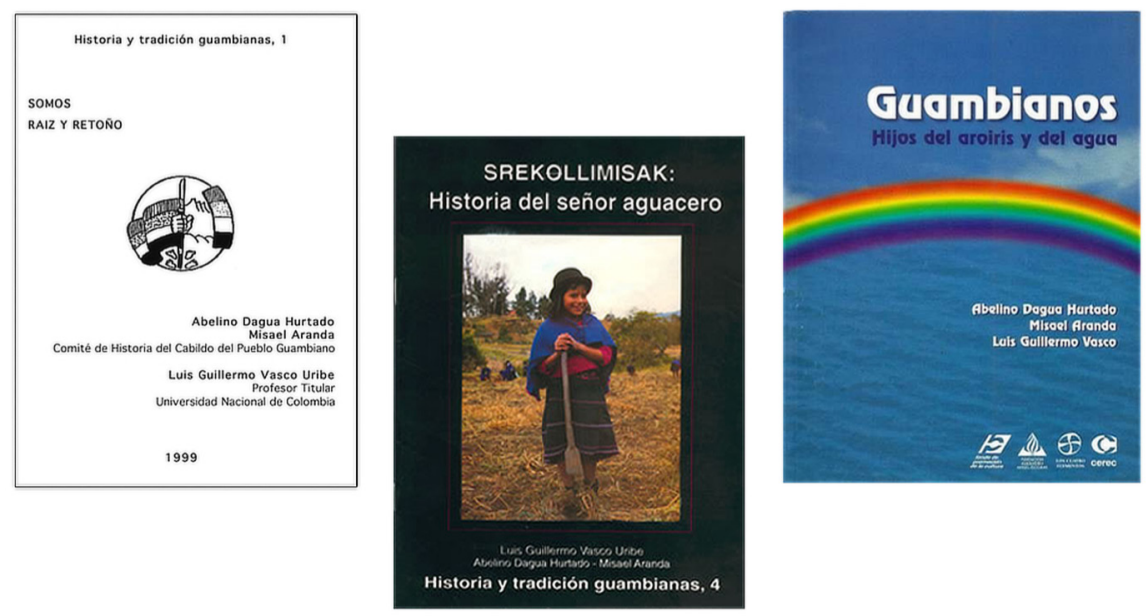

Figura 1. Algumas das cartilhas e livros publicados pelo Comité de Historia del Cabildo Guambiano. Respectivamente: Somos raíz y retoño (Dagua Hurtado; Aranda; Vasco Uribe, 1999), Srekollimisak: historia del señor aguacero (Dagua Hurtado; Aranda; Vasco Uribe, 1994) e a coletânea contendo todos os textos do comitê, Guambianos: hijos del aroiris y del agua (Dagua Hurtado; Aranda; Vasco Uribe, 2015).

Naquilo que possivelmente seja o primeiro registro escrito sobre os grupos indígenas que habitam hoje a porção colombiana da Cordilheira dos Andes, a topografia aparece como elemento primário de consideração. Em 1546, quase 50 anos após a primeira expedição espanhola no atual território colombiano, 0 conquistador e cronista espanhol Pedro Cieza de León assim descrevia a ocupação do território: "[Los indios] están poblados en grandes y muy ásperas sierras, en los valles que hacen tienen sus asientos, y por ellos corren muchos ríos y arroyos" (Cieza de León, 2005, p. 93). Mais à frente, ao descrever a extensão do território da cidade de Popayán, Cieza de León utilizava o exemplo da província de Guambía para sustentar sua descrição: "[terras como] la provincia de Guambía, poblada de mucha gente". Essa pequena sentença segue funcionando, 
nos dias de hoje, como uma das primeiras evidências escritas de que os atuais moradores da região já a habitavam nos primeiros anos pós-Conquista e que, portanto, possuiriam de fato um tipo de laço ancestral com o território de Guambía. É dessa maneira que essa fonte será mobilizada pelo comitê, como evidência histórica de legitimação que, potencialmente, do ponto de vista jurídico e político, contribui com a luta indígena pela recuperação de terras perdidas ao longo dos últimos séculos.

Em um texto publicado pelo Comité de Historia del Cabildo Guambiano (doravante CHCG) em 1989 o trecho em questão surge como demonstrativo de que, ao contrário do que diriam os "historiadores dos terratenientes" (dos proprietários de terra), os Misak não haviam sido "trazidos de outra parte", mas que pertenceriam, na verdade, e desde muito tempo, ao mesmo território. O documento, intitulado Somos raíz y retoño, ressalta que Cieza de León, ao dar à região o qualificativo de província, e já que "isso só era dado a lugares bem povoados, com ampla organização e uma economia abundante", evidenciaria a existência de um considerável desenvolvimento de Guambía já nos primeiros anos do período colonial. Mas antes de recuperar a palavra dos cronistas, os autores propõem uma leitura do passado pré-colonial informada por suas próprias cosmovisões. "Antes", dizem, na lagoa de Piendamú, "o coração da água que permite brotar a vida", "que existe desde sempre", o Pishimisak (espírito ancestral masculino e feminino) "possuía todas as comidas, todos os alimentos". Esse passado ancestral é também o palco das mudanças geológicas do território - fazendo-se confundir, tal qual a natureza do pensamento andino, história humana e história natural:

Los Pishau vinieron en los derrumbes, llegaron en las crecientes de los ríos. Por debajo del agua venían arrastrándose y golpeando las grandes piedras, encima de ellas venía el barro, la tierra, luego el agua sucia; en la superficie venía la palizada, las ramas, las hojas, los árboles arrancados y, encima de todo, venían los niños, chumbados. (Dagua Hurtado; Aranda; Vasco Uribe, 1999, p. 3, grifo dos autores).

O encontro com os espanhóis, a partir da história dos conflitos entre os caciques indígenas e as tropas do conquistador Sebastián de Belalcázar, é descrito como origem das expulsões territoriais e do refúgio em Silvia, cidade 
de onde, mais tarde, seriam novamente expulsos, sendo obrigados a penetrar "a profundeza das montanhas", das quais, "e não se sabe por quantas gerações, viemos nós, os guambianos". A relação construída entre esses dois passados (o passado ancestral dos Pishau e a história dos primeiros conflitos com os europeus) radica-se nem tanto em sua distância temporal, e mais em seu contraste político. Da violência da colonização resultou a morte dos que detinham a sabedoria ancestral, o trabalho com as pedras, o cultivo baseado nos movimentos estelares, o conhecimento do ouro, e a possibilidade de visualizar o tempo “à frente e atrás”. Dos sujeitos que materializavam as conexões temporais entre os Misak do século XVI e seus ancestrais históricos e míticos, como escrevem:

[...] hemos olvidado casi todo. [...] Un manto de silencio cubrió nuestro conocimiento. Ahora, los historiadores de los blancos vienen a decirnos que las huellas de los antiguos que quedan en nuestro territorio no son de los Pishau sino de los pijao, nuestros enemigos. Con ese cuento quieren arrebatarnos a nuestros anteriores, quieren cortar nuestra raíz y separarla de nuestro tronco para poder afirmar su mentira de que no somos de aquí. Eso no es cierto. Los Pishau son nuestra misma gente. Nacieron de la propia naturaleza, del agua, para formar a los humanos. Ellos vienen de Pishimisak que los crió con sus alimentos propios. Por eso, nosotros somos de aquí, de esta raíz; somos Piurek, somos del agua, de esa sangre que huele en los derrumbes. Somos nativos, legítimos de Pishimisak, de esa sangre. No somos venideros de otros mundos. Los blancos... ellos son los venideros. Así hablan nuestros mayores. Esta es nuestra historia. (Dagua Hurtado; Aranda; Vasco Uribe, 1999, p. 6-7, grifo dos autores).

A tentativa de reconstituir a origem histórica em contraponto com o discurso historiográfico nacional ganha, assim, aspectos de um movimento retrospectivo que busca construir, por intermédio de uma contranarrativa, um passado inteligível em comum. A continuidade entre o presente e o passado é estruturada através da identidade em comum entre os Misak de hoje e seus ancestrais Pishau. Para os Misak, a afirmação da ligação ancestral entre as comunidades do presente e os Pishau legitimaria sua existência coletiva no presente, reforçando o uso político desse passado na arena pública da sociedade colombiana. Mas esse procedimento logo dá lugar, no documento do 
comitê, à confrontação entre a evidência das crônicas coloniais e a versão dos acadêmicos. Se não é o objetivo aqui o de reconstruir a história das crônicas coloniais, interessa pensar o lugar que essas crônicas ocupam na narrativa histórica indígena, como uma evidência comprobatória de um pertencimento ancestral ao território. É curioso observar como esse uso, fiel ao que poderíamos chamar de moderno método historiográfico (ou seja, a capacidade da fonte histórica escrita de fornecer evidências para o presente), funciona também como um exercício de crítica à tradição acadêmica nacional.

De fato, alguns historiadores locais de Popayán, como Antonino Olano, haviam defendido, nas primeiras décadas do século $\mathrm{XX}$, a hipótese de que os Misak teriam sido trazidos do Peru ou do Equador como "índios de carga", indígenas Yanacona escravizados, e que teriam chegado à região não antes de 1538, sob mando do capitão Belalcázar (Matallana Peláez, 2013). Fatores como a especificidade da língua dos habitantes de Guambía, com pouca ou nenhuma relação de parentesco com a língua de outros grupos da região, ou mesmo o fato de que Sebastián de Belalcázar havia mesmo empreendido uma viagem entre Quito e Popayán em 1538, trazendo com ele "mais de 5 mil índios de serviço" (Jijón y Caamaño, 1936, p. 165), sustentavam parcialmente essa tese. Parcialmente porque, além dessas percepções primárias, nenhuma evidência concreta que as sustentassem era mobilizada (Schwarz, 2018, p. 55). Tendo sobrevivido por muito tempo principalmente através de sua difusão entre os proprietários de terra e a população não indígena das regiões, a "hipótese Yanacona" parecia alimentar, na interpretação dos historiadores Misak, o interesse de certos grupos sociais de Popayán e Bogotá em legitimar (com a chancela de acadêmicos locais) a ocupação não indígena de Guambía.

O documento do comitê, no entanto, identifica que esse tipo de interpretação ignoraria deliberadamente a palavra dos cronistas espanhóis. Para oferecer uma interpretação alternativa (que pudesse fortalecer a "interpretação própria"), os autores recuperam um documento do historiador e cronista espanhol Antonio de Herrera y Tordesillas, que teria registrado, já em inícios de 1600, a saída de Belalcázar à Quito em 1536, com apenas 300 castellanos, "sem a multidão de índios que costumam levar às jornadas outros capitães" (Dagua Hurtado; Aranda; Vasco Uribe, 1999, p. 13, tradução minha). Dos indígenas capturados pelo espanhol em 1538, o mais provável é que muitos 
tenham padecido na longa viagem. ${ }^{11}$ Na chegada à Popayán os sobreviventes foram instalados em áreas da cidade especialmente reservadas para os Yanacona - e não em Guambía:12 "Los yanaconas llegaron después", concluem os Misak. Em sua interpretação, isso demonstraria que se tratava, afinal, de outro grupo indígena e que, assim, a insistência em tal hipótese só poderia servir para justificar

el despojo de una gran parte de nuestro resguardo con lo que dice, sino también respaldar el hecho de que muchos de los guambianos hayamos sido reducidos a la condición de terrajeros, nuevos indios de servicio, yanaconas modernos, esta vez por y para los terratenientes. (Dagua Hurtado; Aranda; Vasco Uribe, 1999, p. 15).

Uma série de teorias e hipóteses, baseadas tanto na observação dos cronistas coloniais como também em trabalhos historiográficos e linguísticos - cujas conexões com a cosmologia Misak são sempre apontadas -, são percorridas pelo texto do comitê como modos possíveis de contradizer aquilo que denominam "a mentira dos brancos" sobre a origem dos Misak. ${ }^{13}$

Ante nuestra historia tal como la cuentan nuestros mayores, los historiadores de los terratenientes quieren convencernos que no somos de aquí, que somos traídos de otra parte, Pero ni entre ellos mismos logran ponerse de acuerdo sobre el sitio "de donde nos trajeron", ni sobre quién y cuándo lo hizo.

11 A obra da historiadora inglesa Kathleen Romoli Los de la lengua cueva: los grupos indígenas del istmo oriental en la época de la conquista española, de 1987, também é utilizada no texto para referenciar esse argumento.

12 Como confirma Ximena Pachón (1996), os atuais habitantes de regiões indígenas do chamado maciço colombiano, nos resguardos de Río Blanco, Guachicono, Caquiona, San Sebastián e Pancitará, apesar de há muito terem perdido sua antiga língua, suas indumentárias e outros aspectos de sua cultura, se identificam etnicamente como Yanacona.

13 Outras crônicas do século XVI e XVII são utilizadas, no mesmo documento, como comprovações da ocupação ancestral do território pelos Misak. São citados como ratificação do argumento indígena escritos de cronistas tão diversos como os de Juan López de Velasco (1574), do capitão Domingo Lozano, do cronista Fray Pedro de Aguado (1575), do ouvidor Thomas López (1559), do conquistador Pedro de Hinojosa (1569), do ouvidor Diego de Armenteros y Henao (1607) e do governador da então província do Panamá Fernández de Piedrahita (1688). 
Sus afirmaciones chocan de frente con lo que dicen los relatos de los cronistas, españoles venidos entre los primeros y que escribieron sobre los acontecimientos de la conquista. Estos cuentan muy claro que, a su llegada, los conquistadores nos encontraron aquí.

Pero a esos falsos historiadores no les importa; solamente les interesa negar nuestro derecho, justificar el apoderamiento de nuestro territorio por parte de los terratenientes. (Dagua Hurtado; Aranda; Vasco Uribe, 1999, p. 8).

É difícil identificar claramente quem são, afinal, esses "falsos historiadores" (ao longo do texto, as denominações variam: "historiadores brancos", "historiadores de serviço", "historiadores de nossos inimigos", "historiadores dos terratenientes"). Além de Antonino Olano, apenas dois outros historiadores locais são citados, mas com poucas e confusas indicações sobre o conteúdo de seus argumentos. O que parece claro é que, ao se referir a "historiadores", os autores têm em mente não necessariamente a instituição disciplinar (já que fazem um intenso uso de historiadores como fontes para seus argumentos), mas sim a tradição historiográfica local do Cauca do começo do século XX. ${ }^{14}$ Ao buscar contradizer essas e outras hipóteses, e antagonizar posições sobre a história Misak através de um exercício de crítica textual, os membros do comitê localizam uma posição que seria mais política do que científica, já que mais interessada em legitimar os poderes locais do que confrontá-los a partir de evidências históricas - uma apropriação criativa da autoridade histórica derivada dessas mesmas evidências.

O texto finda com um forte apelo sobre como as hipóteses históricas que reafirmariam a não ancestralidade da ocupação Misak ao território de Guambía não possuiriam "nenhuma base científica", além de não terem sido nunca "comprovadas por aqueles que as defendem". O único sentido dessas ideias seria, para os membros do comitê, o fornecimento de um fundamento legitimado historicamente à desapropriação crescente dos territórios indígenas por proprietários de terras ou pelo Estado colombiano. “iiiSOMOS DE AQUÍ!!!”, grafam

14 Esse é o período de formação de uma historiografia profissional na região. A expressão mais difundida dessa historiografia apareceu com a criação do Centro de Estudios Históricos de Popayán, cujo fundador foi o mesmo Antonino Olano, a referência mais antiga mobilizada pelos historiadores indígenas acerca da origem dos Misak como Yanacona. Ver Zuluaga (2002). 
os autores, ressaltando sua convicção, "sustentada por fontes históricas", de um pertencimento ancestral ao território de Guambía.

A crítica indígena é produzida, nesse caso, pelo confronto entre uma certa vertente da historiografia nacional e as crônicas coloniais. A história que interessa, nesse exercício, é a expressão de um interesse específico sobre os aspectos do passado acessíveis em termos de um estudo das evidências escritas. A fonte escrita dos cronistas serviria, assim, em duas frentes: poderia tanto confirmar a hipótese indígena de uma ocupação pré-colonial e, assim, fortalecer a luta política pela garantia do território quanto catalisar um processo de revitalização e socialização da identidade indígena no presente. A importância desse exercício último se conecta com a percepção de que o passado pré-colombiano passa a ser reconhecido como parte integral da herança e memória cultural do grupo e, portanto, fundamentos centrais de sua identidade simbólica. No caso dos Misak, uma demanda como essa se acentua no particular contexto de uma relativa abertura histórica de proliferação de memórias subalternas no tabuleiro da política colombiana, onde elementos de memória cultural e articulação de ("outros") passados têm mais chance de se proliferar como garantias de reconhecimento político e como ferramentas de resistência e visibilização pública.

Se a autonomia local consagrada pelas reformas constitucionais a partir de 1991 forneceram uma espaço possível para esse trabalho de ressignificação, a produção histórica local a partir dos anos 1980, constituída por sua ligação direta com o pertencimento territorial, tanto fez uso das construções ocidentais do passado indígena como confrontou essas mesmas construções a partir de sua agenda étnico-política e da palavra dos mayores (da oralidade). Em síntese, o comitê de história Misak como produtor de uma narrativa que, ao absorver o conhecimento histórico nacional/colonial no interior de um arcabouço conceitual local, encaminha a possibilidade de um fortalecimento da luta do cabildo por autodeterminação política. Esse gesto de confrontação e ressignificação de diferentes expressões históricas será radicalizado em outros textos do comitê, e a possibilidade de contar a história Misak por um ponto de vista temporal próprio será ensaiada mais diretamente, buscando recompor os termos da discussão a partir de uma conceitualização alternativa sobre o que significa propriamente uma experiência temporal - uma passagem da história escrita para a história vivida, da representação à presença da vida. Parece não 
se tratar, então, como tentarei demonstrar a seguir, de um mero "uso político do passado" - uma mobilização alternativa de um mesmo referente histórico que é o "passado" (sendo entendido a partir da compreensão universal da temporalidade). Pelo contrário, a afirmação de uma forma própria de experimentar o tempo lança, para o comitê Misak de história, uma nova exigência para a enunciação de uma história mais relevante em relação às expressões simbólicas e cosmológicas de sua própria experiência.

\section{"A história é um caracol que caminha": tempo como política}

Hablar la historia implica un discurrir que no es lineal, pero tampoco circular. Es como una espiral en tres dimensiones, cuyo centro está en lo alto; los guambianos decimos que es un caracol. Comité de Historia del Cabildo Guambiano

Em um dos textos incluídos em um livro de 1998 organizado pelos membros do CHCG, os autores identificam o tempo e sua interpretação local como um eixo fundamental da experiência histórica dos Misak. A imagem de uma reprodução temporal da comunidade em torno de um "centro" que é a origem, de onde se "desenrola" todo o território vivo, seguindo o movimento de um caracol. O território é vivo, pois, como insistem, não há inanimação estática do nupirau, ele é dinâmico, animado pela força dos seres das águas (nos quais os Misak se inserem): "a dinâmica do nosso território, a vida inteira de nossa sociedade, a existência de cada guambiano, geram um tecido com o fio que une com o centro de tudo" (Dagua Hurtado; Aranda; Vasco Uribe, 2015, p. 56-57, tradução minha). Assim, há de se notar, primeiramente, a conexão fundamental entre o caracol e o território, de modo que a noção temporal de uma espiral "que vai e vem" guarda sua referência mais geral com a simbologia do território na cosmologia local.

Em Guambía, a presença da água, sob a forma das constantes chuvas, dos rios de forte correnteza, das lagoas e dos frequentes arco-íris, fornece um dos elementos fundamentais da configuração mítica e cosmológica dos Misak. Eles se consideram filhos da água. Guambía, aliás, e seu derivativo guambiano, é uma deformação em castelhano da denominação que os Misak se davam 
durante os primeiros anos da conquista: Wampia, a junção de wam (a língua dos Misak) com pi (água), ou seja, o povo da água que fala wam (Escobar, 2019). O mito de origem também expressa a importância originária do elemento, as duas grandes lagoas do território, Piendamú (masculina) e Ñimbe (feminina), sendo concebidas como origem dos primeiros Misak, grandes seres que deram origem à autoridade e à cultura, aos caciques e cacicas. Em tempos antigos, de muita chuva, com deslizamentos de terra (os derrumbes) e inundações, apareceram outros seres. Das feridas (shau) nas montanhas deixadas pela água dos derrumbes, surgiram os humanos ancestrais dos atuais Misak, "raízes dos nativos", "nascidos da água arrastada", "dos restos de vegetação". Os deslizamentos são considerados partos da água dos Pishau, "sábios gigantes que comiam o sal daqui, de nossas próprias fontes de sal, e não eram batizados”. Os Pishau, afinal, como descritos no texto Somos raíz y retoño,

no eran otra gente, eran los mismos guambianos [...] Ellos ocuparon todo nuestro territorio, ellos construyeron todo nuestro nupitrapu antes de llegar los españoles. [...] Grande, hermoso y rico era nuestro territorio. Los españoles lo fueron quitando, hasta arrinconarnos en este corral de hoy: el resguardo. (Dagua Hurtado; Aranda; Vasco Uribe, 1999, p. 3-5, grifo dos autores).

O caracol Misak é muitas vezes explicado com referência à formação geológica desse nupirau, o território ancestral. Em uma reunião na sede do cabildo, em Silvia, pude ouvir de um taita a referência ao território como a materialização do caracol, como o produto dessas águas - agentes cósmicos - que vão e vem ao redor de um centro, uma grande lagoa que desenrola, a partir de si mesma, o resto do território. A dinâmica do movimento das águas não pressupõe um início e um fim. Se a água que vai também volta, assim a história também se "desenrola" (apenas para depois voltar a enrolar-se novamente). O mito de origem expressa um significado específico para a continuidade da existência social: como a lagoa, também a casa é um centro, e dentro dela há outro centro, a cozinha (nak chak), que por sua vez também possui seu próprio centro, o fogão (nak kuk), lugar de irradiação do conhecimento, da tradição, mas também da política e do conflito - a linguista Misak Barbara Muelas Hurtado (1993, p. 23) disse uma vez que, na vida Misak, "o direito nasce das cozinhas". Dessa acumulação de centros possíveis, brota a vida e a história. Mas o centro do caracol não 
é simplesmente um passado temporal, mas origem espacial, e isso muda tudo. Como explicam os membros do comitê:

Ubicar el lugar en donde ocurrieron los orígenes o en donde pasó cada suceso, es fijar un centro y atar el tiempo, es desarrollar una cronología, que significa moverse por ese espacio, recorrerlo; el tiempo fluye, se desenrolla a partir de ese centro, ahí está amarrado el extremo del hilo. Pero ese tiempo se repite y confluye con el presente en la medida en que sigue estando ahí y es escenario de la vida de nuestra gente, como el territorio, la gran casa. En nuestro pensamiento guambiano, al contrario de lo que ocurre en la llamada concepción occidental, el pasado está adelante, es merrap, lo que ya fue y va adelante; wento es lo que va a ser y viene atrás. Por eso, lo que aún no ha sido, viene caminando de atrás y no podemos verlo. (Dagua Hurtado; Aranda; Vasco Uribe, 2015, p. 55-56, grifo dos autores).

O sentido e a direção relacionados aos conceitos de "passado" e "futuros" são organizados aí não por uma lógica linear, progressiva e cumulativa, nem necessariamente por uma circularidade repetitiva, mas por uma constante reorganização do visível/invisível. Se diz que o futuro é o que está atrás porque dele nada pode ser visto. O passado, pelo contrário, possui certa visibilidade. Os vestígios dos antepassados são visíveis, e é tal capacidade (de ser visto) o que produz a possibilidade de visualizar os caminhos a serem explorados nessa tênue linha do presente (moy sro). O "caracol que caminha" reafirma o sentido retrospectivo da experiência coletiva sem relegar o futuro à repetição do mesmo. Ele "caminha" porque toda ação no presente é tanto uma reafirmação do passado quanto um passo cego para a imprevisibilidade e a indeterminação de um futuro que "está atrás", parecendo confirmar a ideia de Marshall Sahlins de que toda fidelidade do presente ao passado é também um gesto de transcendência do mesmo, ou seja, que toda injunção ao presente não é nunca "apenas" reprodução ou mudança, já que em muitos contextos ela pode ser ao mesmo tempo as duas coisas.

Em outro documento elaborado mais recentemente pelo cabildo, explica-se que a inexistência do conceito de tempo elimina da língua e do pensamento a imagem de uma existência permanente, "consagrando [no lugar do 'ser', termo também inexistente em seu idioma] a transitoriedade 
do 'estar"' (Tunubalá; Muelas Trochez, 2016, p. 88, tradução minha). O tempo não aparece, então, como condição externa e independente dos sujeitos: o tempo é alguém fazendo (a si mesmo e o próprio tempo). Como dizem os membros do comitê, "[os Misak] sempre somos uma posição dada no espaço: parados, sentados, deitados, vivendo em algum lugar, etc." (Dagua Hurtado; Aranda; Vasco Uribe, 2015, p. 59, tradução minha). Para Barbara Muelas, uma tal transitoriedade produziria, na linguagem e na cultura própria, um enfraquecimento do conceito de presente:

El concepto del presente, del ahora, /moy/, se refiere a una porción tan pequeña de tiempo que no tiene ninguna dimensión, que no tiene duración; es el instante, el momento, el punto preciso. Es el límite entre el pasado-adelante y el futuro-atrás, que está en continuo movimiento. [...] El presente, /moy sro/, se encuentra entre el tiempo inmediato anterior y el tiempo inmediato posterior. [...] Es un tiempo que apenas está siendo, cuando ya está dejando de ser. (Muelas Hurtado, 1993, p. 35-36).

Seria apressado ver, assim, na afirmação do tempo caracol, um exemplo possível de certa circularidade temporal, representação tão comumente usada para identificar a historicidade indígena, como se sua expressão não passasse de uma espécie de "versão primitiva" do lema ciceroniano que por tanto tempo animou a atividade historiográfica moderna, Historia est magistra vitae, a ação dos sujeitos respondendo diretamente ao valor de um passado datado no tempo. Para os habitantes de Guambía é o contrário, já que, novamente, o centro do caracol nunca é meramente "passado", mas origem, ou raiz. Enquanto organização do visível/invisível, o tempo Misak pode ser definido como experiência espacial: o desenvolvimento temporal responde não a uma tradição constantemente reproduzida de forma idêntica, mas a uma ascendência mítica relativamente aberta, radicada na vibrância do território, e capaz de ser reavaliada de acordo com os requisitos do cotidiano. $\mathrm{O}$ que o caracol apresenta é a possibilidade de percorrer as linhas que se conectam ao centro-origem. Se, como dizem os Misak, o passado é merrap (um passado que está à frente), é porque os ancestrais estavam "abrindo o caminho". Como o futuro está atrás, não é possível vê-lo, o futuro "vem andando por detrás" (wento). Mas não é apenas a partir do centro que as linhas temporais se desdobram, essas linhas também 
retornam ao centro. No lugar de uma espiral de sentido único, são duas, "uma que desenrola e outra que amarra" (Muelas Hurtado, 1993, p. 23).

$\mathrm{O}$ fato de que o tempo Misak aparece descrito através de figuras de espacialidade (o tempo como um caminho o qual se percorre em diferentes sentidos) radica-se na recusa de entendê-lo como entidade abstrata: ele não é domínio do transcendente, mas do imanente. Em sua língua não há um termo equivalente ao de "tempo" como abstração. O termo mais próximo, ote é, na verdade, um indicador de movimento ligado ao sujeito (Peña Bautista, 2009, p. 365). Essa espacialização do tempo, que passa a ser imaginado como um espaço que se percorre em diversos sentidos acaba por produzir também uma conceitualização própria da história. O que muda é que, no caso dos textos publicados pelo comitê, o caracol é descrito não como metáfora conceitual de uma concepção de tempo, mas como o tempo em si. Em conflito com a percepção de antropólogos colombianos sobre o caracol como uma figura de linguagem, os autores sugerem, por exemplo, que "o caracol não é [...] um objeto ou um elemento que substitui outro por algum tipo de relação associativa entre eles, mas sim um conceito. Isso não é expresso por um termo abstrato, por uma palavra, mas, nesse caso, pela casca de um animal; [o tempo] é essa concha" (Dagua Hurtado; Aranda; Vasco Uribe, 2015, p. 60, tradução minha, grifo meu). Ao contrário de uma concepção de tempo baseada na irreversibilidade do passado, movimento replicado na duplicidade do conceito moderno de história (como acontecimento em si e como relato contemporâneo do acontecimento), os eventos referidos no caracol acontecem no interior do processo de narração, sem partição necessária entre a dimensão vivida da história e sua contraparte narrável (a história escrita).

São relativamente recentes as referências etnográficas sobre a composição espiralada do conhecimento local sobre o tempo. Presente nos dias de hoje em calendários escolares, no vestuário, na arquitetura, na interpretação da natureza, ou seja, enquanto elemento fundamental de seu imaginário, o caracol habita um universo de múltiplas representações possíveis da identidade local, onde a reflexão sobre a mudança e a continuidade parecem partir de uma pré-compreensão sobre o lugar do pensamento como uma atividade retrospectiva, "colocando o passado como se estivesse na frente" (Dagua Hurtado; Aranda; Vasco Uribe, 2015, p. 60, tradução minha). A inscrição de vestígios arqueológicos de espirais desenhadas em pedras em Guambía, como demonstrou a arqueóloga Martha Urdaneta Franco $(1988,1991)$ em uma pesquisa colaborativa 
com os Misak (também organizada pelo CHCG), fornece, por sua vez, um tipo de legitimidade temporal da concepção de um futuro que deve se orientar pela origem. É necessário notar, entretanto, que as espirais ou a ideia de "caracol" não aparecem em etnografias mais antigas como elemento digno de comentário por antropólogos ou por missionários que entraram em contato com os habitantes de Guambía. ${ }^{15}$ Isso indica que, se a espiral já fazia parte da constelação de elementos visuais disponíveis, ela não parecia se destacar tanto como acontece desde algumas décadas na região.

O tampalkuari, o sombrero propio, um tipo de chapéu produzido e vestido pelos Misak, é hoje parte da luta local pela preservação de tradições históricas. Na parte de cima, desenhos são tecidos, com imagens e referências visuais de seu universo simbólico: planos cósmicos, pisos térmicos (frio/quente), que formam caminhos espiralados. Outras vezes chamado de kuarimpoto, o chapéu (o sombrero propio) apresenta visualmente a história coletiva da comunidade e a história individual de quem o veste. As linhas seguem o sentido de um caracol e seu movimento de enrolar e desenrolar. As costuras no chapéu representam as etapas da vida individual: infância, juventude ou velhice; mostra se é casado ou solteiro, se tem filhos, de onde vem. Acredita-se que alguns mayores podem ler a história no tampalkuari. Os desenhos, ao revelarem certo sentido temporal, expõem um processo contínuo nunca finalizado por completo, que se expande e se transforma ao longo do caminho, mas que sempre acaba retornando a um centro. Do modo como descreveram alguns pensadores Misak:

Maya es el centro del sombrero propio; en su centro hay uno, un cacique. Elo, va dando todos los colores que rodean el centro, los colores del aroiris. Allí está uno que dirige, que ve todas las cosas. Sale del centro y va girando alrededor, encontrando muchos caminos y organizaciones. Va saliendo pero no sale del todo. Cuando llega al extremo, el cacique Payán va volteando para encontrar otra vez

15 Dois exemplos: em um pequeno livro de interesse cultural de 1949, Nuestra gente: Namuy Misag: tierras, costumbres y creencias de los indios Guambianos, de autoria do antropólogo colombiano Gregório Hernández de Alba e do Misak Francisco Tuminã-Pillimue, não há menções sobre espirais ou caracóis (cf. Hernández de Alba; Tuminã-Pillimue, 1949). Da mesma maneira, em uma clássica etnografia de Ronald Schwarz (2018), que conduziu pesquisas de campo em Guambía nos anos 1960, não há nenhum registro sobre a presença de espirais na cultura material ou imaterial dos indígenas. No entanto, além dos petróglifos de espirais, há diversos registros de espirais impressas em antigas cerâmicas e outros vestígios. Cf. ainda Botero Páez (1984) e Rappaport (1990). 
el centro. Y se devuelve por el mismo hilo, el tom, que lo devuelve hasta llegar al mismo centro. (Dagua Hurtado; Aranda; Vasco Uribe, 2015, p. 174, grifo dos autores).

A antropóloga Joanne Rappaport (2005, p. 153), em um rico estudo sobre a atividade de "intelectuais nativos" no Cauca colombiano (não só os Misak, como também os Nasa e outros grupos em torno do Consejo Regional Indígena del Cauca) fala das espirais como ferramentas conceituais que buscariam produzir um sentido científico-acadêmico para a experiência cotidiana dos grupos - com o objetivo de legitimar a concepção de tempo própria através do uso de figuras matemáticas, por exemplo. Ao mesmo tempo, a espiral forneceria um poderoso instrumento conceitual a ser empregado na atividade política. Espirais (ou caracóis) como gerações teóricas que, no entanto, só "ganham vida" no interior das disputas sociopolíticas do presente. Rappaport aborda assim as espirais como "veículos teóricos", como elementos que tornam possível a constituição de uma visão alternativa, promotora de novos discursos e novas práticas indígenas; elementos necessários para o desenvolvimento de proposições políticas indígenas em torno de uma nação (que se afirma como) multicultural.

No caso dos Misak, outros momentos, que não será possível analisar aqui, parecem confirmar a ideia de um processo autoconsciente de reapropriação cultural nos termos de uma luta política a partir dos anos 1980. Os estudos da língua nativa por estudiosos Misak (Muelas Hurtado, 1993; Gonzales Castaño, 2012), esforços arqueológicos colaborativos entre acadêmicos e indígenas (Urdaneta Franco, 1988, 1991), a "judicialização" da linguagem política (Cabildo del Pueblo Guambiano, 2007; Muelas, 2000; Tunubalá; Muelas Trochez, 2016) e o desenvolvimento de uma pedagogia intercultural (Aranda et al., 2012) são outras apresentações desse mesmo impulso, florescente na história recente de Guambía, que busca equipar politicamente a comunidade e sua organização com um modelo para a disseminação (interna e externa) de seu framework cosmológico.

\section{Conclusão}

Logo no começo das terras de Guambía, quando se chega por Silvia, há uma construção recente, e sua arquitetura imita a espiral do tampalkuari. Ali funciona, desde 2011, a Ala Kusreik Ya, uma universidade Misak, outro resultado 
dos projetos de reconstrução cultural ascendentes a partir da década de 1980 (ver Avila; Ayala, 2017). A universidade é administrada pelo cabildo e seu currículo (estruturado ao longo de quatro anos) compreende uma série de questões focadas na especificidade dos saberes indígenas, em temas variados como economia, ecologia, matemática e sociologia. O taita Trino Morales, coordenador pedagógico da universidade na época em que visitei o resguardo, explicava que, como reafirmação dos saberes tradicionais em processo de recuperação, as espirais são objetos constantes de investigação na universidade, e aplicados conceitualmente nas mais variadas temáticas, "em assuntos de história, é claro, mas também nas 'ciências da vida', na matemática, em questões climáticas". ${ }^{16}$ Em sua sala, o calendário escolar da universidade disposto na parede organiza os meses do ano em uma dupla espiral. Ali também, como no caso da prática historiográfica Misak, a remissão da atividade (pedagógica ou histórica) aos conceitos "próprios" visa reorganizar o campo das sensibilidades coletivas, transpondo fronteiras sobre o dizível e o indizível, sobre o visível e o invisível.

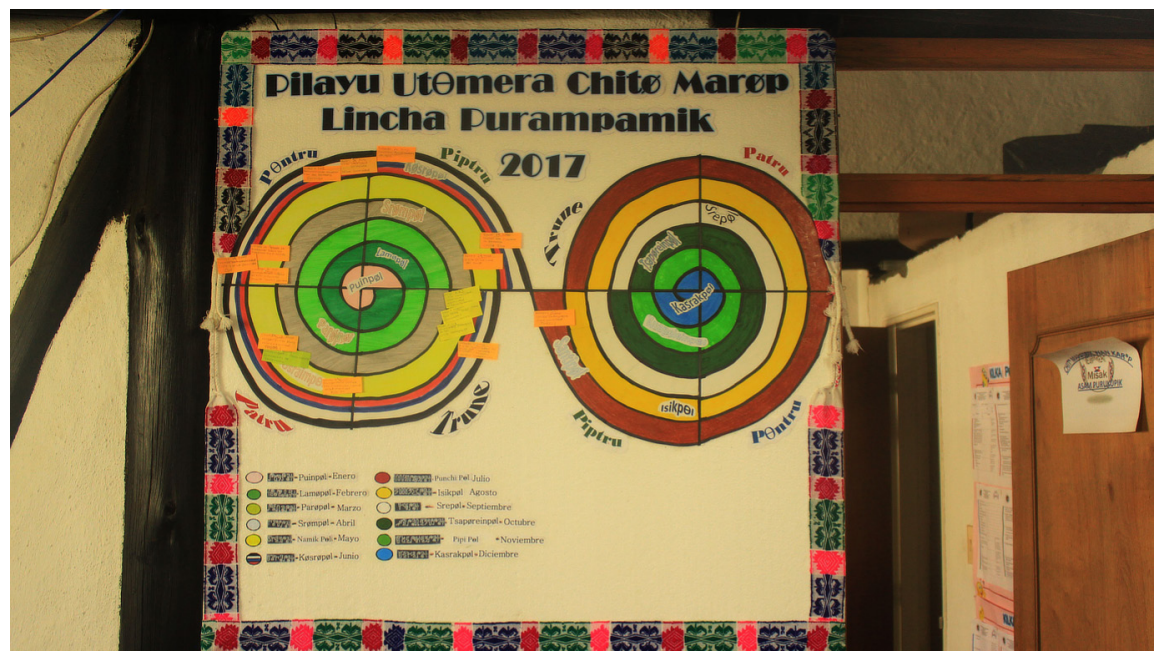

Figura 2. O calendário do ano de 2017 na Universidad Misak. Foto: Guilherme Bianchi, 2017.

16 Entrevista com Trino Morales na Universidad Misak, cabildo de Guambía, 15 de junho de 2017. 
Nos textos do CHCG, o valor de verdade da palavra escrita pelos cronistas espanhóis é mobilizado como indício de justificação histórica e jurídica, como uma apropriação politicamente orientada do saber produzido pelos europeus. Contudo, não é só a apropriação dos registros de arquivo que liga a produção Misak à forma e ao espírito epistemológico moderno, a própria forma acadêmica de apresentação dos argumentos, a língua escolhida para o documento, sua publicação em revistas acadêmicas da Colômbia, são todos fios que conectam a experiência local com padrões à primeira vista externos à comunidade. Mas, "por mais modernas que possam parecer" (como disse Paul Gilroy para o caso das práticas de representação cultural e religiosa afro-americanas), há algo de efetivamente extramoderno também nas representações historiográficas em Guambía. É essa duplicidade - o fato de que essas práticas estão inevitavelmente "tanto dentro como fora da proteção duvidosa que a modernidade oferece" - que determina a especificidade de uma conceitualização que faz coexistir formas diferentes de conhecimento (Gilroy, 2001, p. 130). O conteúdo do passado (do passado mítico dos ancestrais e do passado histórico cuja fonte são as crônicas) é elaborado narrativamente de modo a permitir o confronto entre o que dizem diferentes sujeitos coletivos sobre o passado indígena.

O enunciado "a história é um caracol que caminha", por exemplo, não apenas descreve o entendimento local dos processos históricos, como amplia as linhas de contato entre o conhecimento temporal "próprio" e aquele, o "histórico", construído externamente. A reapropriação das crônicas coloniais como fonte de legitimação histórica, por sua vez, é também a realização de um realinhamento do regime que define quem pode (e quem não pode) escrever a história dos Misak - um rompimento com o que identificam ser a lógica circular do conhecimento acadêmico. Além disso, os experimentos teóricos também devolvem, para a disputa política, novos termos possíveis para a imaginação local, para o enquadramento da experiência coletiva indígena e para a projeção de estratégias de ação no presente. A história escrita pelos Misak não apenas multiplica a variedade de versões históricas sobre o passado, muito menos instaura uma versão definitiva sobre ele. O que ela produz é uma comunicação por diferença. Ele não busca, assim, cancelar esse desentendimento entre a história dos historiadores locais e a história indígena, mas tornar tal desentendimento mais visível e, portanto, mais controlável. Não se trata, como lembrou Viveiros de Castro (2004, p. 10), de "desfazer o equívoco (uma vez que isso seria 
supor que ele nunca existiu em primeiro lugar)", mas de enfatizá-lo, de "abrir e ampliar o espaço que se imagina não existir entre as linguagens conceituais em contato".

No caso das reflexões onde a especificidade das formas de temporalização indígena substitui a pragmática do argumento historiográfico, há a reivindicação de um entendimento particular do tempo, irredutível às categorias formais do tempo histórico moderno que o primeiro movimento (o uso político das crônicas) parece tomar como evidente. A espiral permite que os historiadores indígenas conceitualizem as narrativas orais através de representações históricas que não são lineares, nas quais a forma é produzida com o objetivo de recapturar, para o texto, o movimento espiralado do tempo manifestado pela oralidade. Nesse caso, a ligação formativa com a epistemologia moderna dá lugar a um exercício normativo que reconstitui as linhas de força que ligam estratos distintos do tempo. O caracol Misak do tempo, articulado teoricamente nos textos do comitê, é, dessa maneira, também um gesto discursivo de contestação temporal e de afirmação existencial, contra a hegemonia de um tempo linear e absoluto, comum tanto ao discurso histórico quanto ao aparato nacional/estatal. ${ }^{17}$ Além disso, esses experimentos teóricos também devolvem, para a disputa política, novos termos possíveis para a imaginação local, para o enquadramento da experiência coletiva indígena e para a projeção de estratégias de ação no presente.

É verdade que uma interpretação focada exclusivamente no produto textual da atividade política indígena (os textos do CHCG) está limitada desde o início a ser uma abordagem bastante pontual da experiência desses povos. Como lembrou Rappaport (2005, p. 155), a vasta maioria das experimentações teóricas e textuais de grupos indígenas não necessariamente culminam em textos escritos, mas muito mais em práticas políticas, em agências individuais e coletivas, em performances sociais que povoam o cotidiano de pessoas reais.

17 Como recentemente apontou o historiador belga Berber Bevernage (2012, p. 108, tradução minha): “Apesar de suas claras vantagens intelectuais, a noção de um tempo absoluto, vazio e homogêneo e o raciocínio cronológico que se baseia nisso dificilmente podem explicar a pluralidade de noções de tempo 'vividas' ou 'subjetivas' e não podem integrar experiências temporais que são não lineares ou 'não contemporâneas'. Devido às suas ambições universalistas, o tempo absoluto, vazio e homogêneo não só de fato manifesta uma incapacidade de integrar experiências diferentes de tempo, mas também uma intolerância direta a outras temporalidades." 
Não haverá mais tempo aqui para medir a distância entre os significados textuais manejados pelos intelectuais Misak e a organização política que envolve a criação desses mesmos significados, mas creio ter sido possível demonstrar como o trabalho de investigação histórica e o trabalho de criação de conceitos (expressos via texto) possibilitam desde já a contemplação de uma divergência de perspectivas sobre o tempo. Essa divergência é o que institui um espaço possível para a consideração dos procedimentos cotidianos de memória em grupos que compartilham formas diferentes de nomear o passado, o presente e o futuro.

\section{Referências}

ACOSTA, G. La esperanza y el espejo: el plan integral de vida del pueblo guambiano. 2013. Trabajo de grado (Antropología) - Facultad de Ciencias Humanas, Universidad Nacional de Colombia, Bogotá, 2013.

ARANDA, M. et al. Parosoto, sembrando cultura ayer, hoy y siempre: una propuesta educativa propia para la pervivencia del pueblo Misak. Popayán: Editorial Universidad del Cauca, 2012.

AVILA, S. A.; AYALA, Y. A. Ala Kusreik Ya-Misak Universidad: construyendo educación propia. Jangwa Pana, v. 16, n. 1, p. 54-66, 2017.

BEVERNAGE, B. History, memory, and state-sponsored violence: time and justice. New York: Routledge, 2012.

BOTERO PÁEZ, S. Tras el pensamiento y pasos de los taitas guambianos: intentos de aproximación a su historia, siglos XVI, XVII, XVIII. 1984. Trabajo de grado (Antropológía) - Universidad Nacional de Colombia, Bogotá, 1984.

CABILDO DEL PUEBLO GUAMBIANO. Manifiesto guambiano. Silvia, 1980. Disponível em: https://alakusreikya.files.wordpress.com/2013/10/manifiesto-guambiano. pdf. Acesso: 15 set. 2019.

CABILDO DEL PUEBLO GUAMBIANO. Plan de vida del pueblo guambiano: programas y proyectos. Silvia, 1994.

CABILDO DEL PUEBLO GUAMBIANO. Misak Ley, por la defensa del derecho mayor, patrimonio del pueblo Misak. Silvia, 2007. Disponível em: https://www.grain.org/es/ article/entries/1241-misak-ley. Acesso: 15 set. 2019. 
CHILITO, E. A. Poblaciones indígenas y elecciones locales en cuatro municipios del Departamento del Cauca 2003-2015. Colombia Internacional, n. 94, p. 143-175, 2018.

CIEZA DE LEÓN, P. Crónica del Perú: el señorío de los incas. Caracas: Biblioteca Ayacucho, 2005.

COLOMBIA. Ley 89 de 1890 (Noviembre 16). Por la cual se determina la manera como deben ser gobernados los salvajes que se reduzcan a la vida civilizada. Bogotá, 1890. Disponível em: https://www.mininterior.gov.co/sites/default/files/4_ley_89_ de_1_8_9_0.pdf. Acesso em: 12 set. 2019.

DAGUA HURTADO, A.; ARANDA, M.; VASCO URIBE, L. G. Srekollimisak: historia del señor aguacero. Bogotá: Gente Nueva Editorial, 1994. (Historia y tradición guambianas, 4).

DAGUA HURTADO, A.; ARANDA, M.; VASCO URIBE, L. G. Somos raiz y retoño. 2. ed. Cali: Ediciones Colombia Nuestra, 1999. (Historia y tradición guambianas, 1).

DAGUA HURTADO, A.; ARANDA, M.; VASCO URIBE, L. G. Guambianos: hijos del aroiris y del agua. 2. ed. Bogotá: CEREC, 2015. (Historia y tradición guambianas, 5).

ESCOBAR, D. El ciclo sagrado de las altas cumbres: agua, vida y pensamiento entre los misak (guambianos). Antípoda: Revista de Antropología y Arqueología, Bogotá, n. 34, p. 145-151, 2019.

GILROY, P. O Atlântico negro: modernidade e dupla consciência. São Paulo: Editora 34, 2001.

GONZÁLEZ, M. El resguardo en el Nuevo Reino de Granada. Bogotá: La Carreta, 1979.

GONZALES CASTAÑO, G. ¿Quién necesita una lengua? Política y planificación lingüística en el departamento del Cauca. Tabula Rasa, n. 17, p. 195-218, 2012.

HERNÁNDEZ DE ALBA, G.; TUMIÑA-PILLIMUE, F. Nuestra gente: Namuy Misag: tierras, costumbres y creencias de los indios guambianos. Popayán: Instituto Etnológico Nacional: Universidad del Cauca, 1949.

HERRERA ÁNGEL, M. Ordenamiento espacial de los pueblos de indios. Dominación y resistencia en la sociedad colonial. Fronteras de la Historia, v. 2, n. 2, p. 93-128, 1998.

JIJÓN Y CAAMAÑO, J. Sebastián de Belalcázar. Quito: Imprenta del Clero, 1936.

MATALLANA PELÁEZ, S. Yanaconas: indios conquistadores y colonizadores del Nuevo Reino de Granada, siglo XVI. Fronteras de la Historia, v. 18, n. 2, p. 21-45, 2013. 
MUELAS, L. El derecho mayor no prescribe. Revista Ecología Política, n. 19, p. 99-104, 2000 .

MUELAS HURTADO, B. Relación espacio-tiempo en el pensamiento guambiano. Proyecciones Lingüísticas, v. 1, n. 1, p. 31-40, 1993.

PACHÓN, X. Los guambianos y la ampliación de la frontera indígena. In: CAILLAVET, C.; PACHÓN, X. (dir.). Frontera y poblamiento: estudios de historia y antropología de Colombia y Ecuador. Lima: Institut français d'études andines, 1996. p. 283-314.

PARRADO MORALES, S.; ISIDRO, L. La paradoja hipócrita. Problematización de la participación política de la mujer misak. Colombia Internacional, n. 80, p. 135-170, 2014.

PEÑA BAUTISTA, J. A. En las voces del Pishimisak: apuntes etnográficos sobre el tiempo misak. Maguaré, n. 23, p. 343-369, 2009.

RAPPAPORT, J. The politics of memory: native historical interpretation of the Colombian Andes. New York: Cambridge University Press, 1990.

RAPPAPORT, J. Intercultural utopias: public intellectuals, cultural experimentation, and ethnic pluralism in Colombia. Durham: Duke University Press, 2005.

RAPPAPORT, J.; GOW, D. The multiple idioms of modernity in native Cauca. In: WARREN, K. B.; JACKSON, J. E. (ed.). Indigenous movements, self-representation, and the state in Latin America. Austin: University of Texas Press, 2003. p. 47-80.

SÁNCHEZ BOTERO, E. Reflexiones en torno de la jurisdicción especial indígena en Colombia. Revista del Instituto Interamericano de Derechos Humanos, v. 41, p. 225-250, 2005.

SÁNCHEZ GUTIÉRREZ, E.; MOLINA ECHEVERRI, H. Documentos para la historia del movimiento indígena colombiano contemporáneo. Bogotá: Ministerio de Cultura, 2010.

SCHWARZ, R. A. La gente de Guambía: continuidad y cambio entre los Misak de Colombia. Popayán: Editorial Universidad del Cauca, 2018.

TUNUBALÁ, F.; MUELAS TROCHEZ, J. B. Segundo plan de vida de pervivencia y crecimiento misak: Mananasrøkurri. Mananasrønkatik. Misak Waramik. Bogotá: Dígitos y Diseños, 2016.

TUNUBALÁ, J.; PECHENÉ, L. 518 años de resistencia, 200 años de lucha de los pueblos. El deber, el derecho de reexistencia y libertad. Maguaré, n. 24, p. 415-426, 2010.

TURNER, T. Da cosmologia à história: resistência, adaptação e consciência social entre os Kayapó. Cadernos de Campo, São Paulo, v. 1, n. 1, p. 68-85, 1991. 
URDANETA FRANCO, M. Investigación arqueológica en el resguardo indígena de Guambía. Boletín del Museo del Oro, n. 22, p. 55-81, 1988.

URDANETA FRANCO, M. Huellas de pishau en el resguardo de Guambía. Boletín del Museo del Oro, n. 31, p. 3-30, 1991.

VASCO URIBE, L. G. Así es mi método en etnografia. Tabula Rasa, n. 6, p. 19-52, 2007.

VIVEIROS DE CASTRO, E. Perspectival anthropology and the method of controlled equivocation. Tipití: Journal of the Society for the Anthropology of Lowland South America, v. 2, n. 1, art. 1, 2004.

YRIGOYEN FAJARDO, R. Pluralismo jurídico, derecho indígena y jurisdicción especial en los países andinos. El Otro Derecho, n. 30, p. 171-195, 2008.

ZULUAGA, F. U. Los historiadores del Cauca. Revista Historia y Espacio, n. 18, p. 133$162,2002$.

Recebido: 17/09/2019 Aceito: 27/04/2020 | Received: 9/17/2019 Accepted:4/27/2020 